\title{
El derecho fundamental al debido proceso Vs. Procedimiento sancionatorio entre particulares
}

\author{
The fundamental right to due process $V$ s. \\ Sanctioning procedure between individuals
}

https://doi.org/10.15332/iust.v0i17.2424

\author{
Christel Catherine Duarte Chávez. \\ Abogada, Especialista en Derecho Procesal, Universidad Santo Tomás Bucaramanga. \\ Rama Judicial - Juzgado Catorce Civil Municipal de Bucaramanga \\ Correo electrónico: cduartec@cendoj.ramajudicial.gov.co
}

\begin{abstract}
Resumen
El propósito del texto es ahondar sobre conceptos jurídicos procesales y laborales respecto del procedimiento sancionatorio realizado a los trabajadores con ocasión de lo previsto en el artículo 115 del C.S.T., y desarrollado por la Corte Constitucional en Sentencia C-593 del 2014, al analizar los derechos y deberes que le asisten a las partes envueltas dentro de una relación laboral al momento de llevarse a cabo un procedimiento disciplinario, esto es, el empleador quien se encuentra facultado para imponer sanciones tenga en cuenta los parámetros que conforman el debido proceso con el fin de no menoscabar las garantías de defensa que tienen los empleados sometidos a un proceso sancionatorio; y en particular plantear una posición jurídica que abarque instituciones procesales desde una óptica constitucional, bajo el cual se entienda satisfecho el derecho del empleado a debatir en una segunda instancia el resultado del procedimiento que se le adelantó.
\end{abstract}

Palabras clave: Reglamento de trabajo, potestad disciplinaria y procedimiento sancionatorio

\begin{abstract}
The purpose of the text is to delve into procedural and labor legal concepts regarding the sanction procedure performed on workers on the occasion of the provisions of article 115 of the CST, and developed by the Constitutional Court in judgment C-593 of 2014, when analyzing the rights and duties that assist the parties involved in an employment relationship at the time of carrying out a disciplinary procedure, that is, the employer who is empowered to impose sanctions take into account the parameters that make up the due process in order to not undermine the defense guarantees that employees undergo a sanctioning process; and in particular to propose a legal position that includes procedural institutions from a constitutional perspective under which the right of the employee to debate in a second instance the outcome of the procedure that was advanced to him is understood satisfied.
\end{abstract}

Keywords: Labor regulations, disciplinary power and sanction procedure. 


\section{Résumé}

Le texte a pour objet de se plonger dans les notions de procédure et de droit du travail relatives à la procédure de sanction appliquée aux travailleurs à l'occasion des dispositions de l'article $115 \mathrm{du}$ CST, développées par la Cour constitutionnelle dans l'arrêt C-593 de 2014, lors de l'analyse des droits et les devoirs qui assistent les parties impliquées dans une relation de travail au moment de mener une procédure disciplinaire, c'està-dire que l'employeur qui est habilité à infliger des sanctions tient compte des paramètres qui composent la procédure régulière afin de ne pas porter atteinte aux garanties de la défense que les employés subissent un processus de sanction; et en particulier de proposer une position juridique qui inclut les institutions procédurales d'un point de vue constitutionnel en vertu duquel le droit de l'employé de débattre en deuxième instance du résultat de la procédure qui lui a été avancée est compris comme satisfait.

Mots-clés: Réglementation du travail, pouvoir disciplinaire et procédure de sanction. 


\section{El derecho fundamental al debido proceso Vs. Procedimiento sancionatorio entre particulares ${ }^{1}$}

Christel Catherine Duarte Chávez

\section{INTRODUCCIÓN}

Uno de los derechos trasversales dentro de un Estado social de derecho gravita esencialmente en el debido proceso, entendido este, en términos simples, como un compendio de criterios mínimos que protegen a las personas de acciones arbitrarias o injustificadas, previsto en el canon 29 de la Carta Política, el cual ha sido ampliamente desarrollado por el alto tribunal constitucional, distinguiendo como elemento constitutivo de este; al menos en materia penal, disciplinaria y en acciones de tutela, el principio de la doble instancia, que igualmente se encuentra señalado en el artículo 31 de la Carta Magna, y los cuales deben predicarse no solo de las actuaciones judiciales sino también en las administrativas, donde se vean involucrados los particulares a quienes se le haya otorgado la posibilidad de imponer sanciones; en el caso de los empleadores, dicha potestad se encuentra reglada en el artículo 115 del Código Sustantivo del Trabajo y desarrollada por la Corte Constitucional en Sentencia C-593 del 2014 al indicar que el Reglamento Interno de Trabajo de una empresa debe contemplar y regular el procedimiento para la imposición de las sanciones disciplinarias, es así como el último de los siete elementos consignados por el cuerpo colegiado dispone que, el trabajador tiene la oportunidad de replicar a través de los recursos a que haya lugar, las determinaciones que se tomen en el interior del procedimiento sancionador ante el superior jerárquico que impone la sanción, supuesto que carece de claridad, como quiera que se enfrentan dos posiciones, una es que dicha garantía se satisface con la opción de acudir a la jurisdicción laboral ordinaria, y la otra, es que dentro de la misma empresa deba existir quien revise la idoneidad de la sanción impuesta, disyuntiva que genera incertidumbre, puesto que lo resuelto por la corporación no expresa de forma precisa si la doble instancia a la que hace alusión debe surtirse frente a quien ostente un cargo superior al de la persona que decidió en primera vara, o por el contrario, la inconformidad en cuanto a la decisión sancionatoria debe ser ventilada en la jurisdicción ordinaria.

Igualmente se hará alusión a un caso del año 2018 que se gestó en esta ciudad, siendo objeto de contienda judicial a través de la acción de amparo, correspondiéndole

$1 \quad$ El presente texto es producto del desarrollo del trabajo de investigación, realizado en la asignatura Metodología de la Investigación - Especialización en Derecho Procesal 2018 - 2019. El trabajo conto con la asesoría temática del docente Elbert Enrique Gómez Ustaris, asesoría metodológica de la docente Denisse Herreño Castellanos. Universidad Santo Tomás Bucaramanga. 
a un juzgado civil municipal despachar la diligencia en primera instancia, para conocer la alzada un juzgado civil del circuito; estrado que finalmente, al contrario de lo que entendía la empresa accionada mediante su representante legal, considero que informarle al empleado que puede agotar el procedimiento sancionatorio ante la justicia laboral, no asegura el principio de la doble instancia, dando a entender que lo preceptuado por la jurisprudencia constitucional es que dentro de una entidad del sector privado debe crearse una segunda instancia que dirima las objeciones en un proceso sancionatorio, por tanto, lo planteado se circunscribe a determinar, a partir de un análisis constitucional, el alcance de las garantías procesales de las que goza un empleado dentro de un procedimiento sancionatorio.

\section{DESARROLLO NORMATIVO DEL PRINCIPIO DEL DEBIDO PROCESO}

La piedra angular sobre la cual se edifica la confianza en el derecho procesal no es más que el principio del debido proceso, por cuanto ello legitima la funcionalidad de cualquier Estado normativo para luego enfocarlo hacia su importancia en el área del derecho disciplinario, comoquiera que, dentro de este ámbito comporta la garantía de la doble instancia como regla general, situación que no está demás aclarar, no ocurre en otros escenarios.

El compendio que regula la cuestión objeto de análisis, para el efecto refiérase en primer lugar a los tratados internacionales, como fuente innegable que ha vertido la legislación nacional, de esta forma, la Convención Americana sobre Derechos Humanos (Pacto de San José) en su artículo $8^{\circ}$ dispone un listado de garantías judiciales, a su turno el artículo 14 del Pacto Internacional de Derechos Civiles y Políticos reconoce las mismas garantías en el ámbito del derecho penal, instrumentos que justifican la protección internacional al tener como fundamento los atributos de la persona humana, y que tienen como propósito promover el respeto universal y efectivo de los derechos y libertades humanos.

Descendiendo al caso patrio, el artículo 29 de la Constitución prevé la base iusfundamental que rige toda actuación judicial y administrativa, extendida por abierta doctrina jurisprudencial a las relaciones entre particulares; siendo el debido proceso, un principio en el cual se subsumen otros más, y que ha sido definido por la Corte Constitucional como un:

Conjunto de garantías previstas en el ordenamiento jurídico, a través de las cuales se busca la protección del individuo incurso en una actuación judicial o administrativa, para que durante su trámite se respeten sus derechos y se logre la aplicación correcta de la justicia (Sentencia C-341, 2014).

En la misma sentencia el alto tribunal señaló las garantías que hacen parte del debido proceso, las cuales son: 
(i) El derecho a la jurisdicción, (ii) el derecho al juez natural, (iii) el derecho a la defensa, que comprende los medios legítimos y adecuados para ser oído y obtener una decisión favorable, como la asistencia de un abogado cuando sea necesario, a la igualdad, buena fe y a la lealtad procesal, (iv) el derecho a un proceso público, desarrollado dentro de un tiempo razonable sin dilaciones injustificadas; (v) el derecho a la independencia del juez, y (vi) el derecho a la independencia e imparcialidad del juez o funcionario.

\section{EL DERECHO AL DEBIDO PROCESO EN MATERIA DISCIPLINARIA}

De cara al esquema planteado, se expone una pequeña introducción cronológica para entender la naturaleza de la disciplina, y el derecho disciplinario, aunado a que dicha labor, ayuda a comprender la inescindible relación entre la evolución del comportamiento social y su incidencia en la esfera jurídica, seguido del abordaje normativo. Para el caso en revisión, en el texto: Los tipos sancionatorios en blanco en el proceso disciplinario. Un análisis desde el debido proceso, su autor, Jonatham Zapata, (2017, p. 178- 179), cita a Joan Manuel Trayter (1991, pp. 34-35-36); y GómezValencia (2006, pp. 684-687).

"En el contexto ibérico nacen las primeras manifestaciones del derecho disciplinario en la Baja Edad Media con la aparición de los primeros aparatos burocráticos. $\mathrm{Se}$ atribuyeron a los oficiales reales ciertas competencias que devinieron en la instauración de un sistema de responsabilidad por los actos cometidos en el ejercicio de sus funciones y la imposibilidad para el rey de separar unilateralmente a los servidores de sus cargos"... Más adelante, en el período colonial, se establece una serie de instituciones con la finalidad de afianzar una gerencia eficaz, justa y leal de los funcionarios de la Corona en tierras iberoamericanas. Nacen la visita, el juicio de residencia, la pesquisa y la purga de taula como medios de la Corona para controlar la gestión de los administradores en América. En los pueblos indígenas la disciplina se ha instaurado a través de sus autoridades tradicionales. "Es así como en el caso de los pueblos andinos colombianos perviven instituciones de carácter prehispánico y colonial encargadas de establecer formas de control y de enjuiciar los comportamientos de sus miembros. No es un sistema centralizado, pues en la base coexisten diferentes sistemas de autoridad como los taitas, los chamanes, los médicos tradicionales que tienen potestades disciplinarias específicas".

Al hilo de lo expuesto, el mandato jurídico que sirve de sustento se encuentra previsto en el artículo 6 de la Constitución, que preceptúa: “Los particulares sólo son responsables ante las autoridades por infringir la Constitución y las leyes. Los servidores públicos lo son por la misma causa y por omisión o extralimitación en el ejercicio de sus funciones".

Para decirlo en breve y de forma puntual, la responsabilidad de los particulares se ciñe únicamente a la infracción de una norma, de forma tal, que el derecho disciplinario 
se sirve de los diferentes compendios, llámese reglamentos, leyes, estatutos, manuales de convivencia, etc., los cuales entrañan facultades y prohibiciones cuyo objeto sea fijar parámetros que permitan a un cierto conglomerado delimitar sus comportamientos, definir sus faltas y establecer las consecuencias de su trasgresión.

Conforme a la contextualización histórica y normativa precedente, así como teniendo en cuenta la panorámica del debido proceso, es menester encausar sus particularidades dentro del ámbito disciplinario, para ello, es preciso determinar que, la facultad sancionadora "entendida como la prerrogativa de un sujeto para imponer sanciones o castigos" (Sentencia T-433, 1998) reside principalmente en cabeza del Estado, expresándose a través de distintas modalidades, entre las que se halla el derecho disciplinario, y este a su vez, hace parte del género, denominado derecho administrativo sancionador, ahora, puntualmente el primero se manifiesta "en la potestad de los entes públicos de imponer sanciones a sus propios funcionarios, con el propósito de preservar los principios que guían la función administrativa señalados en el artículo 209 constitucional (moralidad, eficiencia, celeridad, igualdad, economía, imparcialidad y publicidad)" (Sentencia T-1034 de 2006) y cuya meta es preservar el cumplimiento de las disposiciones establecidas en el ordenamiento jurídico, mediante la imposición de sanciones que censuren y eviten aquellas conductas contrarias al mismo.

No obstante, el artículo 29 de la Constitución apuntala:

"El debido proceso se aplicará a toda clase de actuaciones judiciales y administrativas".

Lo que traduce que, itérese, si bien la facultad sancionadora se encuentra en cabeza del Estado, ello no obsta, para que cualquier sujeto al cual, la ley le haya otorgado esa potestad, pueda hacer uso de ella con el fin de mantener el orden, como es el caso de los particulares dentro de las asociaciones, planteles educativos o los empleadores, de ahí que, se reconocen distintas formas del derecho sancionador, de acuerdo con los sujetos intervinientes, intereses y efectos jurídicos, lo que presupone un trato diferenciador, aun cuando también compartan elementos comunes, que son, los principios y reglas constitutivas del derecho penal.

Justamente la doctrina constitucional señala como elementos que conforman el debido proceso en materia disciplinaria, los siguientes:

(i) el principio de legalidad de la falta y de la sanción disciplinaria, (ii) el principio de publicidad, (iii) el derecho de defensa y especialmente el derecho de contradicción y de controversia de la prueba, (iv) el principio de la doble instancia, (v) la presunción de inocencia, (vi) el principio de imparcialidad, (vii) el principio de non bis in idem, (viii) el principio de cosa juzgada y (ix) la prohibición de la reformatio in pejus (Sentencias T-1034 de 2006 y C-593 de 2014). 


\section{Del principio de la doble instancia}

De lo expresado con antelación se arriba al punto de inflexión principal; el principio de la doble instancia, consagrado en el canon 31 de la Constitución, que tal y como se advirtió, si bien tiene un vínculo estrecho con el debido proceso no hace parte del contenido esencial de este, puesto que la opción de impugnar una sentencia desfavorable no es una regla general que se aplique a todos los ámbitos del derecho, comoquiera que, el citado canon establece en cabeza del cuerpo legislativo la facultad de restringir este principio formulando excepciones, de forma que, existen dentro del ordenamiento asuntos que ya sea por su cuantía o naturaleza son de única instancia, reservándose el derecho a apelar la decisión judicial únicamente en materia penal y en acciones de tutela, que además a voces del alto tribunal constitucional no contraviene los tratados firmados y ratificados que hacen parte del bloque de constitucionalidad, habida cuenta que, la Convención Interamericana o el Pacto de Derechos Civiles y Políticos de las Naciones Unidas prevén este derecho en materia penal, sin que se haga extensiva a otros campos del derecho.

Respecto del asunto el cuerpo colegiado ha sido enfático al señalar que el principio de la doble instancia carece de un carácter absoluto:

Esta Corporación ha sostenido de manera reiterada, que del contenido normativo del artículo 31 de la Constitución, se deduce que no es imprescindible e imperativa la aplicación de la doble instancia en todos los asuntos que son materia de decisión judicial o administrativa, puesto que la ley se encuentra habilitada para introducir excepciones, siempre y cuando sean razonables y proporcionales, no vulneren el derecho a la igualdad y respeten las garantías constitucionales fundamentales del debido proceso, como lo son, los derechos de defensa, de contradicción y de acceso a la administración de justicia (...).

- A partir de las citadas consideraciones, la Corte ha determinado que la posibilidad de apelar una sentencia desfavorable y, por ende, de asegurar la existencia de una segunda instancia, no hace parte del contenido esencial del debido proceso ni del derecho de defensa (Sentencia C-095/03).

En ese orden de ideas, la ley puede consagrar excepciones a la doble instancia, salvo cuando se trata de sentencias penales condenatorias o de fallos de tutela, los cuales siempre podrán ser impugnados, según los artículos 29 y 86 de la Carta. Esto significa que, en materia penal, la Constitución ordena que todos los procesos sean de doble instancia, con la única excepción de aquellos casos en donde la propia Carta establece fueros especiales, que implican un juicio penal de única instancia, como es el caso de los congresistas, que son investigados y juzgados en única instancia por la Corte Suprema de Justicia (Sentencia C-040/02). 
De cara al desarrollo de este principio, el cuerpo colegiado en Sentencia C-213 de 2007 efectuó un análisis de este y extrajo varias reglas para establecer su alcance en el ordenamiento constitucional, y que para el efecto se trae a colación solo una, por cuanto hace énfasis en el propósito que cumple, a saber:

(v) El sentido y razón de ser de la doble instancia no se vincula tanto con la mera existencia en el plano institucional y funcional de una jerarquía vertical de revisión ni tampoco se relaciona en exclusiva con la simple gradación jerarquizada de instancias que permitan recurrir, impugnar, controvertir. La doble instancia no es un fin en sí misma sino un instrumento para garantizar los fines supremos a los que está vinculada la actividad estatal y se dirige a asegurar la existencia de una justicia acertada, recta y justa, en condiciones de igualdad.

De las disquisiciones esbozadas refulge palmario que, aunque el principio del debido de la doble instancia no es absoluto, conforme lo preceptuado en los artículos 29 y 31 de la Constitución se consagra como regla general dentro del ámbito sancionador, al tratarse de una garantía que asegura la legalidad del ius puniendi.

\section{DERECHO SANCIONADOR EN LAS RELACIONES LABORALES ENTRE PRIVADOS}

Se colige entonces que, con el fin de cumplir otros componentes axiológicos de la constitución los dos principios antes señalados tienen eco en todos los asuntos en los que se haga uso de la potestad disciplinaria, interpretación que ha efectuado la corporación constitucional, al señalar que, itérese en todas las áreas en las que se haga uso de la potestad disciplinaria deben acatarse las formas mínimas que conforman el debido proceso, habida cuenta que dicho mandato se extiende no solo a las autoridades públicas sino también a los particulares a los que la ley les otorga la prerrogativa de imponer sanciones.

Es así como, la ya citada Sentencia T-433-98 expone:

El artículo 29 de la Carta Magna dispone que el debido proceso se aplicará a toda clase de actuaciones judiciales y administrativas. Esta norma constitucional, ha de entenderse para toda clase de actuaciones de carácter administrativo que han de seguir las empresas ya sea del sector público, bien del sector privado, cuando van a ejercer su poder sancionatorio frente a un trabajador, por la supuesta ocurrencia de una falta que amerite una sanción contemplada bien sea en la ley o, en los reglamentos internos de trabajo.

Ya esta Corporación ha manifestado que las facultades sancionatorias de que gozan los empleadores frente a sus trabajadores deben ser ejercidas en forma razonable y proporcional a la falta que se comete $\mathrm{y}$, además con el rigorismo de estar plenamente probados los hechos que se imputan.

Comoquiera que estamos frente a relaciones laborales entre privados, la norma aplicable en este caso es el Código Sustantivo del Trabajo, el cual prevé que el 
reglamento de trabajo debe determinar las condiciones a que deben sujetarse el empleador y sus trabajadores en la prestación del servicio y de contera el procedimiento para imponer sanciones, de forma particular el artículo 115 de esta codificación indica que con antelación a imponer la sanción se debe escuchar al trabajador inculpado, y si este sí pertenece al sindicato, también a dos representantes del sindicato al cual pertenezca, de lo contrario la sanción no surtirá efecto alguno.

No obstante, para fines prácticos la norma en cita presenta inconvenientes dada la falta de regulación expresa o específica que efectúe una guía para el empleador de manera uniforme, tan es así, que la regla jurídica fue objeto de demanda de inconstitucionalidad, resuelta mediante Sentencia C-593-2014, concluyendo en dicha providencia el alto tribunal que la facultad disciplinaria del empleador se encuentra supeditada y no puede trasgredir los derechos fundamentales de los empleados, debiendo garantizar las prerrogativas mínimas que contiene el artículo 29 del Estatuto Constitucional, y que venían siendo desarrolladas en sentencias anteriores para las actuaciones administrativas.

Dentro del texto Introducción al despido disciplinario - Derecho laboral chileno - Poder de Dirección del Empleador, de Lupo Hernández Rueda, se identifica lo que comprende esta potestad, se tiene entonces que:

El poder de dirección reconocido al empleador comprende una pluralidad de facultades que el ordenamiento jurídico reconoce como necesarias e indispensables para el funcionamiento normal de la empresa, para su organización económica, técnica y funcional. Esto se traduce, en hecho y en derecho, en la facultad de dar órdenes, impartir instrucciones y trazar directivas, en la facultad de legislar en el seno de la empresa, en la facultad de imponer sanciones disciplinarias y en diversas facultades o derechos (de control, de ordenar la empresa, de variar las condiciones de trabajo), reconocidos al empleador como necesarios para conducir la empresa. (Hernández, 2013, p. 405).

A su turno, en el escrito El Poder Disciplinario Laboral se justifica la relación entre el derecho disciplinario y el penal, como aporte indispensable para entender las semejanzas y diferencias entre éstos, de cara a concebir cómo se estructuran los principios del poder sancionatorio del derecho penal al disciplinario en las relaciones entre particulares, al exponerlas de la siguiente forma:

En verdad el poder disciplinario no es más que el ejercicio de un derecho peculiar a los grupos sociales o instituciones que se constituyen dentro de la sociedad política, derecho este que actualmente tiene ya su autonomía: el Derecho disciplinario. Ese Derecho disciplinario es, en último análisis, un verdadero Derecho penal de las instituciones, pues tiene, de hecho, una semejanza en la igualdad de naturaleza entre el crimen y la falta de disciplina, ambos factores de desorganización den una colectividad. Entretanto, el Derecho penal y el Derecho disciplinario presentan una diferencia de orden esencial, pues ambos castigan faltas en sociedades que difieren una de otra por su naturaleza (De Mesquita, 2013, p. 14). 
Lo anterior resulta una acotación de relieve, en la medida en que esgrime las garantías que desarrolla el debido proceso y que no son las mismas en todos los ámbitos del derecho, por consiguiente, con el fin de entender y delimitar este poder, se ha enfatizado que, como cualquier facultad disciplinaria, se encuentra intrínsecamente unida al derecho penal, dicho de otro modo, el procedimiento que debe surtirse, así como los principios que deben aplicarse dentro del derecho disciplinario ejercido por los empleadores son similares al derecho penal.

Por otro lado, la jurisprudencia constitucional ha señalado que la potestad disciplinaria que ejerce el empleador sobre sus trabajadores es un elemento de la subordinación, es decir, el poder de dirección en la actividad laboral que se manifiesta en las órdenes e instrucciones y la imposición de reglamentos, relacionadas con las funciones y obligaciones que debe acatar el trabajador para cumplir con los objetivos de la empresa, deviene necesariamente de la subordinación como factor constituyente y distintivo del contrato de trabajo.

En cuanto a la limitación, las actuaciones adelantadas en virtud de la potestad disciplinaria deben respetar el derecho fundamental al debido proceso, dado que, para la Corte Constitucional es indispensable que "los entes de carácter privado fijen unas formas o parámetros mínimos que delimiten el uso del poder disciplinario" (Sentencia T-944 de 2000), esto significa que "en todos los campos donde se haga uso de la facultad disciplinaria, entiéndase ésta como la prerrogativa de un sujeto para imponer sanciones o castigos, deben ser observados los requisitos o formalidades mínimas que integran el debido proceso (Sentencia T-433 de 1998) y que deben ser fijados en los reglamentos, manuales de convivencia o estatutos, puesto que esa es la justificación de su existencia.

Respecto de este mismo asunto, el artículo publicado en la revista Opinión Jurídica, denominado el "Debido proceso y procedimiento disciplinario laboral", robustece aún más este concepto, al sostener su autor que:

De lo anterior, se desprende la obligación de los empleadores de respetar el debido proceso, dada su naturaleza de derecho fundamental en el ordenamiento jurídico colombiano, durante el impulso de una investigación disciplinaria, cuyo desenlace sea la imposición de una sanción, puesto que esta es una garantía que reconoce que toda persona:

'Tiene derecho a que su juicio se adelante según reglas predeterminadas, por el tribunal o autoridad competente y con todas las posibilidades de defensa y de contradicción, habiendo sido oído el acusado y examinadas y evaluadas las pruebas que obran en su contra y también las que constan en su favor' (Sentencia T-470 de 1999). Tejada, 2016, p. 230).

Así pues, nótese que la potestad disciplinaria laboral debe sujetarse a las prerrogativas mínimas previstas en el artículo 29 de la Constitución Política y que forman parte del debido proceso, razón por la que, el cuerpo colegiado constitucional ha reiterado en varias oportunidades qué elementos conforman itérese, esos "mínimos". 


\section{PRINCIPIO DE DOBLE INSTANCIA DENTRO DEL PROCEDIMIENTO SANCIONATORIO LABORAL}

En virtud del análisis de constitucionalidad del artículo 115 del Código Sustantivo del Trabajo que dispone la obligación de ser escuchado al trabajador antes de imponérsele una sanción disciplinaria, el cuerpo colegiado se pronuncia mediante Sentencia C-593 de 2014, así:

En este orden de ideas, la jurisprudencia constitucional ha establecido el conjunto de elementos mínimos que debe contemplar el Reglamento Interno de Trabajo al regular el procedimiento para la imposición de las sanciones disciplinarias que en él se contemplen, entre los que se encuentran:

i) la comunicación formal de la apertura del proceso disciplinario a la persona a quien se imputan las conductas posibles de sanción,

ii) la formulación de los cargos imputados, que puede ser verbal o escrita, siempre y cuando en ella consten de manera clara y precisa las conductas, las faltas disciplinarias a que esas conductas dan lugar y la calificación provisional de las conductas como faltas disciplinarias. Acá debe recordarse que el mismo Código Sustantivo del Trabajo dispone que tanto la conducta como su respectiva sanción debe encontrarse previamente consagradas en el Reglamento Interno del Trabajo,

iii) el traslado al imputado de todas y cada una de las pruebas que fundamentan los cargos formulados,

iv) la indicación de un término durante el cual el acusado pueda formular sus descargos, controvertir las pruebas en su contra y allegar las que considere necesarias para sustentar sus descargos,

v) el pronunciamiento definitivo del patrono mediante un acto motivado y congruente,

vi) la imposición de una sanción proporcional a los hechos que la motivaron; y

vii) la posibilidad que el trabajador pueda controvertir, mediante los recursos pertinentes, todas y cada una de las decisiones ya sea ante el superior jerárquico de aquél que impone la sanción como la posibilidad de acudir a la jurisdicción laboral ordinaria.

De la sentencia de constitucionalidad anotada, el último ítem es el de interés, comoquiera que establece el principio de doble instancia dentro del procedimiento sancionatorio laboral, no obstante, se ha efectuado una búsqueda exhaustiva de casos relacionados con este punto, lo cierto es que, poco se ha encontrado de forma precisa, sin embargo, en dicha providencia se reiteró que con ocasión a lo prescrito en el artículo 29 de la Constitución, las empresas privadas en uso de su facultad disciplinaria frente a un trabajador deben aplicar con estricto rigor el debido proceso para dirimir aquellas controversias originadas en faltas que conlleven sanciones contempladas en la ley o en los reglamentos internos; para ello referencio de forma 
sucinta algunos casos, que dada su pertinencia se anotarán brevemente, en Sentencia T-385 de 2006, la Corte al resolver el caso concreto, "reiteró que el trabajador tiene derecho a conocer los hechos que y tener la oportunidad de defenderse"; en la T-083 de 2010, estimó la corporación que era necesario que "los entes privados fijaran unos parámetros mínimos que delimitaran el uso del poder y bajo los cuales las personas podían conocer las condiciones por las que se rige su relación con ese privado" y debían "especificar cada una de las etapas procesales de manera que las sanciones no queden sujetas al simple arbitrio de los encargados de tomar las decisiones"; en la T-075A de 2011, el cuerpo colegiado adujo que el debido proceso rige para toda clase de actuaciones judiciales y administrativas, adelantando un procedimiento previamente establecido y conocido (...), pero que algunas de las garantías que se derivan de este derecho se aplican al ámbito de las relaciones laborales particulares. Entre estas (...) la obligación del empleador de indicar los motivos por los cuales se imponen sanciones sujetas al Reglamento Interno.

Adicionalmente a la sentencia arriba aludida, existe un pronunciamiento judicial concreto y que se relaciona de forma directa con el propósito del texto, el cual fue emitido por el Juzgado Tercero Civil del Circuito de Bucaramanga. En esa oportunidad el despacho resolvió una segunda instancia en sede de tutela en la cual se debatieron las circunstancias bajo las cuales un trabajador entiende satisfecho el principio a la doble instancia al interior de un procedimiento sancionatorio dentro de su empresa. Postura que no se comparte. En esa providencia el fallador (reformule el texto con signos de puntuación) indicó:

El despacho no tiene de recibo las justificaciones de la empresa accionada donde manifiesta que le dio cabal cumplimiento a los parámetros establecidos en la jurisprudencia nacional vigente, a través de la remisión a la actora de la comunicación fechada el 15 de mayo de 2017, por cuanto no tuvo oportunidad, ni se le concedió de forma expresa el término para agotar cada una de las etapas establecidas para el procedimiento disciplinario, por lo que no puede afirmar la accionada que con un solo escrito se perfeccionó todo el trámite, el cual debe contar con actuaciones administrativas que permitan establecer el inicio y la culminación de cada etapa procesal, además de manifestar en su decisión los recursos de Ley de los cuales es susceptible, toda vez que informarle que puede agotar el procedimiento ante la justicia ordinaria, no prevé el principio de la doble instancia.

La contienda se suscita entre una empleadora y su trabajadora, quien dentro de un procedimiento sancionatorio en el interior de la entidad fue despedida por haber cometido una falta, sin embargo, al emitir dicha sanción la empresa le comunicó que si no se encontraba conforme con la decisión, siempre podía acudir a la vía judicial, y con ello se entendía satisfecho el requisito que sentó la corporación constitucional en Sentencia C-593-2014, este es, "la posibilidad de que el encartado pueda controvertir, mediante los recursos pertinentes, todas y cada una de las decisiones", empero precisamente el fallador de segunda vara claramente expreso "además de manifestar en su decisión los recursos de Ley de los cuales es susceptible, toda vez que 
informarle que puede agotar el procedimiento ante la justicia ordinaria, no prevé el principio de la doble instancia", sin embargo, de la lectura de ese fallo, no se observa que haya referenciado un precedente más allá de la sentencia de constitucionalidad antes citada, y emitido una interpretación del alcance del debido proceso y del último requisito establecido por la Corte, de ahí que no se comparta la tesis esgrimida por el operador judicial.

Se plantea una postura distinta, teniendo en cuenta los parámetros constitucionales antes estudiados, entendiendo que el principio de la doble instancia aun cuando no es absoluto, es parte integrante del debido proceso y si bien, el mismo es necesario para que los trabajadores puedan controvertir las sanciones a las que son sometidos, este se entiende satisfecho con la advertencia de poder acudir a la jurisdicción laboral a impugnar esa decisión; comoquiera que es el juez quien tiene el deber de evaluar imparcialmente los hechos que dieron lugar a la controversia y determinar si la decisión adoptada se ajusta a derecho, y de contera proceder a remediar la situación, habida cuenta que la doble instancia no es un fin en sí mismo, su propósito no se dirige a jerarquizar una institución, sino a garantizar el cumplimiento del valor constitucional de justicia, y para lograr este cometido no es necesario crear funciones o cargos dentro de una empresa para absolver segundas instancias en torno a un procedimiento disciplinario, cuando es el operador judicial el servidor idóneo para resolver dichos conflictos y determinar en todo caso, la extralimitación o no del poder sancionatorio del empleador, es decir, no porque dentro de una entidad no se establezca un superior que revise la sanción, genera como consecuencia lógica la contravención de derechos fundamentales de los empleados, como sí, se le impone una carga al empleador carente de una fuente constitucional y legal, por cuanto el trabajador no queda desprotegido, la vía ordinaria es el escenario apropiado para debatir dichos asuntos, es más, si se tratase de defender una teoría garantista, es dentro de un proceso judicial el contexto adecuado para salvaguardar el derecho al debido proceso y defensa, porque está dotado de etapas que permiten exponer y evidenciar los elementos de juicio con el propósito de dirimir la contienda protegiendo los derechos de ambos extremos, de ahí que, acudir ante un juez de la república es la forma como se materializa el valor de justicia intrínseco a la doble instancia.

\section{REFERENCIAS}

Cardona, J. E. (2012). Modelo hermenéutico del debido proceso en Colombia, en Revista Estudios de Derecho, Vol 69, Núm. 153, pp. 215 - 244. Universidad de Antioquia. Medellín, Col.

Constitución Política de Colombia, 1991, artículos 6, 29 y 31. Segunda edición corregida de la Constitución Política de Colombia. Gaceta Constitucional, No. 116 de 20 de julio de 1991.

Convención Americana Sobre Derechos Humanos (Pacto de San José) San José, Costa Rica 7 al 22 de noviembre de 1969. 
Corte Constitucional, Sala Séptima de Revisión, T-1034 de 2006. Magistrado Ponente: Humberto Antonio Sierra Porto, Bogotá D. C., cinco (5) de diciembre de dos mil seis (2006).

Corte Constitucional, Sentencia C-095/03. Magistrado Ponente: Rodrigo Escobar Gil, Bogotá, D.C., once (11) de febrero de dos mil tres (2003).

Corte Constitucional, Sentencia C-213/07. Magistrado Ponente: Humberto Antonio Sierra Porto, Bogotá, D.C., (21) de marzo de 2007.

Corte Constitucional, Sentencia C-341/14. Magistrado Ponente: Mauricio González Cuervo, Bogotá, D.C., 4 de junio de 2014.

Corte Constitucional, Sentencia C-593/14. Magistrado Ponente: Jorge Ignacio Pretelt Chaljub, Bogotá D. C., veinte (20) de agosto de dos mil catorce (2014).

Corte Constitucional, Sentencia T-433 de 1998, Sala Primera de Revisión. Magistrado Ponente: Dr. Alfredo Beltrán Sierra, Bogotá, veinte (20) de agosto de mil novecientos noventa y ocho (1998).

De Mesquita, L. J. (s.f.). El poder disciplinario laboral. Recuperado el 5 de mayo de 2019, de http://www.cepc.gob.es/Controls/ $\mathrm{Mav} / \mathrm{get} \mathrm{Data}$. as h $\mathrm{x}$ ? M AVqs $=\sim$ aW $9 \mathrm{MjkzNTAmaWR} 1 \mathrm{PTE}$ w M zcm d X J P T Ew J m 5 hbW U9U1B T X z Aw OV 8 w M D k u GR m Jm Z p b G U 9 U 1 B T X z Aw OV 8 w M D k u c GR m Jn R h Y m x h P U F ydGljdWxvJmNvbnRlbnQ9YXBwbGljYXRpb24vcGRm

Hernán, C. F., y Alzate, N. (s.f.). El procedimiento disciplinario que deberán establecer los empleadores. Recuperado el 12 de mayo de 2019, de https://www. ambitojuridico.com/noticias/informe/educacion-y-cultura/el procedimientodisciplinario-que-deberan-establecer-los.

Hernández, L. (2013). Introducción al despido disciplinario - Derecho laboral chileno. Poder de Dirección del Empleador. Recuperado el 5 de mayo de 2019, de http://www.emiliokopaitic.cl/2018/04/introduccion-al-despido-disciplinario. html https://drive.google.com/file/d/1LPkyCg9Tqjmjg83C6rtbTNuRkoRTuV Gc/view

Ministerio del Trabajo. (2015). Recuperado el 12 de mayo de 2019, de http://www. mintrabajo.gov.co/documents/20147/48305/168688++Procedimiento+Disciplin ario+sector+Privado.pdf/0de49127-1de0-3791-74e0-5d4c8390f969?download

Pacto Internacional de Derechos Civiles y Políticos, 23 de marzo de 1976.

Tejada, J. G. (2016, julio-diciembre). Debido proceso y procedimiento disciplinario laboral. Opinión Jurídica, 15(30), 227-248. ISSN 1692-2530. Medellín, Colombia. Recuperado el día 5 de mayo de 2019 de la base de datos V|LEX.

Zapata, J. (2017). Los tipos sancionatorios en blanco en el proceso disciplinario. Un análisis desde el debido proceso, Opinión Jurídica, 16(31), 175-196. ISSN 16922530, Medellín, Colombia. Recuperado el día 5 de mayo de 2019, de la base de datos V|LEX. 